\title{
Friedrich Hölderlin: "Sobrepasamiento de límites” y "el mundo en el mundo" (1)
}

Friedrich Hölderlin es un poeta y filósofo que por lo general no está relacionado con la "praxis" del mundo vital: formado en el círculo de los filósofos que luego serían conocidos como representantes del "Idealismo alemán", cursó estudios intensivos de Kant y Fichte, estudios de Literatura y Filosofía antigua y, por supuesto, también de Teología.

Al aura del "genio trágico" y del "excéntrico genial", apartado de la vida y que ofrece todo tipo de proyecciones, contribuye ciertamente a su sinuoso y complejo curriculum vitae: constantemente rechazado por los clásicos Goethe y Schiller, especialmente por este último, el "padre supremo", en dependencia psíquico-emocional respecto a él, huyendo de Jena, de las lecciones de Fichte, enamorado incurablemente de Suzette Gontard, esposa de banquero, perteneciente a la alta burguesía, cuyo hijo educó e instruyó en la casa de su empleador; Suzette Gontard, muerta en ausencia de Hölderlin. Hay que mencionar también una madre que lo limitó y presionó, oscuras perspectivas laborales, penurias económicas, dependencia y luego aquel "final" como poeta mentalmente turbado y "trastornado" en la posteriormente denominada "Torre Hölderlin". Después de haber sido ingresado en la clínica psiquiátrica Autenrieth (una de las primeras de Alemania) y de salir meses después en calidad de "incurable", fue cuidado por el maestro carpintero Zimmer en la casa directamente al lado del río Neckar, donde el carpintero tenía su taller. El poeta enfermo, vivió en la habitación superior, en un mirador con forma de torre, y pasó sus días, en parte visitado por antiguos amigos y admiradores, cantando, tocando el piano, mirando el valle del Neckar, "poetizando" y visitando el taller de su tutor. Si tenía visita, tendía en parte a un rechazo tajante, en parte a gestos teatrales-cortesanos, que hacían oscilar a los visitantes entre sentimientos de desprecio, de no tomarlo en serio y de compasión con el "genio enfermo".

A esto hay que añadir que solo pocos de sus escritos fueron publicados, lo cual puede haberse debido a su radicalidad e intransigencia al pensar y escribir. La

(1) El presente artículo es la reelaboración de la conferencia dictada por la Prof. Hiller el 24 de septiembre de 2008 en el coloquio "Hölderlin-Heidegger", organizado por la Universidad Alberto Hurtado (Chile). El artículo fue traducido al castellano por el Prof. Roberto Rubio. La visita de la Prof. Hiller, así como la traducción del texto, tuvieron lugar en el marco de los Proyectos Fondecyt 11060023 y 7080030 . 
mayor parte de los escritos que contribuyeron a la fama posterior de Hölderlin fueron transmitidos mediante manuscritos y eran, en cuanto a su apariencia, a su expresión lingüística y en parte también en cuanto a su "contenido", poco apropiados para el público en general, herméticos, incomprensibles, oscuros.

Sin embargo, como han demostrado las investigaciones del siglo pasado, una mirada más precisa muestra que detrás de esto se esconden elementos complejos, en parte incluso en los límites de lo pensable y decible, elementos que, por otro lado, muestran en última instancia una claridad y profundidad de pensamiento casi sin parangón.

Llama la atención que Hölderlin, por una parte, se encuentre en el campo de influencia de la filosofía de Kant y Fichte -de modo que valga como representante de la "filosofía clásica alemana", del llamado "Idealismo alemán"- y que, por otra, sus estudios intensivos de la filosofía y poesía de la antigua Grecia lo hayan impulsado en una dirección que constituye su destacada modernidad. En oposición a la dirección de Hegel, quien en su "Dialéctica" apunta teleológicamente hacia la fundamentación del concepto absoluto así como del Espíritu Absoluto -y con ello hacia unidad e identidad-, el planteo trascendental de Hölderlin está caracterizado originariamente por algo distinto, a saber: por el pensar (y ipoetizar!) la diferencia. Esto hace a Hölderlin no solo un pensador destacadamente "moderno". Con ello se abren también posibilidades para enriquecer, en el campo de la ciencia de la cultura, la discusión actual acerca de la "alteridad" y del "ser otro", como también la discusión sobre interculturalidad, dado que Hölderlin no solo capta originariamente la relación entre identidad y diferencia, entre lo "uno" y "lo otro", lo "propio" y lo "ajeno", sino que también la capta trascendentalmente, es decir, desde sus condiciones de posibilidad. De esto resultan consecuencias también en relación a las figuras del "sobrepasamiento de límites" y del "mundo en el mundo", que dan el título al presente trabajo.

I.

El difícil texto poetológico de Hölderlin, titulado "El modo de proceder del espíritu poético" (2), si bien apunta a la fundamentación trascendental de la poesía, refiere básicamente a la posibilidad del "conocimiento", del "mundo" y a la "Antropología”. En el centro se encuentra la relación entre identidad y diferencia. Desde allí se tematizan dinámicas vinculadas con la formación de "mundo/mundos", "comunidad/comunidades", "cultura/culturas", así como con su influencia recíproca en sus respectivas diferencias.

Despleguemos el lado "práctico" de Hölderlin desde su lado teórico, trascendental. El "espíritu" - un concepto central de Hölderlin así como de la filosofía del Idealismo Alemán- es para Hölderlin siempre algo de dos caras: es un órgano central del hombre, que abarca toda facultad humana, y es a la vez un órgano que sobrepasa, precisamente por ello, al hombre como individuo. También en su modo 
de agitación y efectuación él es doble, y además opuesto internamente, contradictorio en sí mismo: por una parte separa, es analítico, mientras que por otra parte une, es sintético.

El proceso poético, el proceso del poetizar, es un proceder y obrar del espíritu. De acuerdo a la determinación de "espíritu" antes mencionada, se trata de algo que potencialmente lo abarca todo. Pero más importante es la realización efectiva del espíritu, del acto poético y del poema: de las condiciones de posibilidad de esa realización trata el texto sobre "El modo de proceder...". A su vez, estas reflexiones trascendentales están atravesadas por reflexiones no transcendentales, "empíricas". A través de ello se fija y establece en el texto cómo y a partir de qué presupuestos debe operar el espíritu (poético) para realizarse a sí mismo y a su "otro mismo": el poema y el "mundo". Aquí hay que considerar que para Hölderlin el proceso poético no es un proceso entre otros, sino que el poetizar es el proceso propiamente humano, en el cual el hombre recién puede formarse a sí mismo como individuo y a "su mundo" como "su mundo" y plenificar su destino en el mundo.

Este proceso poético es, como se ha presupuesto ya en el concepto de espíritu, abarcante, "total", abarcante tanto del yo como del mundo. De este proyecto totalizador, de esta "totalidad" del espíritu se podría derivar una pretensión de totalidad o también de totalitarismo. Esto significaría que el "espíritu" es precisamente lo omniabarcante, lo que está a la base de todo, lo que condiciona todo, lo "uno" absoluto. Afirmar esto teóricamente podría justificar, en lo práctico, un planteo social y político totalitario, totalitarista.

Pero no ocurre esto en Hölderlin. Porque se puede argumentar que si el espíritu, tal como lo hemos caracterizado, abarca tanto al espíritu individual, al "espíritu humano", como al "espíritu del mundo", entonces es siempre un espíritu dividido en sí mismo, nunca un mero "uno". Pero esto no basta, porque incluso si el "espíritu" se "manifiesta" o está presente en todo esto, entonces sería, sin embargo, una especie de "ultra" o "superespíritu", que constituye y condiciona todo. "El espíritu" permanecería entonces como el espíritu uno e idéntico consigo mismo. Tampoco basta la indicación de que el espíritu es doble y opera doblemente, es decir, tanto analítica como sintéticamente, porque también aquí podría tratarse de un espíritu que efectúa y abarca todo esto en sí. Tenemos entonces un problema con el célebre Geist del idealismo alemán.

Consideremos de cerca el proceso espiritual destacado por Hölderlin, el proceso del poetizar en sus condiciones fundamentales, en sus condiciones de posibilidad que a la vez son las de su realización. A partir de la conformación del espíritu resulta, según Hölderlin, que el espíritu no puede subsistir "para sí", que siempre necesita de otro en relación hacia él -volveremos sobre esto más adelante-. En el nivel más bajo del proceso poético, ese otro es el material, aquello que ha de ser tratado en el poema, aquello de lo cual debe tratar el poema. En el proceso ulterior, ese otro se amplía y es denominado "círculo efectual" o "elemento". En el progreso del proceso poético se necesitan otros cada vez más abarcantes.

Pero ¿qué "hace” el espíritu con estos otros? Él los capta. ¿Qué significa esto? "Captar" significa para Hölderlin -esto es un aspecto decisivo-, que esto otro debe ser "ante todo", es decir, de un modo especial, "receptivo" para el espíritu, o sea, que el espíritu no solo puede captar todo lo que quiera y en igual medida, sino que, 
del lado de lo otro, del lado de lo que debe ser "captado", debe haber un autorización para ser captado. En esto se muestra, por una parte, un límite de la "omnipotencia" del espíritu, y se ve, por otra parte, que se trata de una capacidad y actividad recíproca, del espíritu y de lo "otro". Las "relaciones de fuerza" están pues repartidas. El espíritu debe averiguar qué otro es particularmente apropiado para ser captado, la "receptividad" de lo otro respecto al espíritu muestra un escalonamiento gradual. De esta gradación se puede derivar que también debe ser posible que algo no se pueda captar (al menos en un determinado momento y en una determinada constelación).

A partir de estos supuestos de la captación resultan las relaciones fundamentales en el proceso del captar. Para Hölderlin, el captar lo otro no consiste en el sometimiento de lo otro respecto al espíritu, ni en su superación en el espíritu, sino que lo otro, al estar captado por el espíritu, deviene otro respecto de sí mismo, algo "espiritual", y por otra parte -y este es el punto decisivo- permanece, sin embargo, otro respecto al espíritu, algo "no-ideal". Al ser captado por el espíritu, lo otro no pierde su alteridad y a la vez, no obstante, deviene otro respecto de sí mismo, volviéndose justamente un "sí mismo".

Esto suena paradójico, pero es lógico, si seguimos los presupuestos fundamentales. Vamos paso a paso: ¿Por qué lo otro deviene algo espiritual al ser captado por el espíritu? Por una parte, porque el espíritu solamente así puede captar, solo puede captar espiritualmente, él es espíritu. ¿Qué pasa entonces con lo otro? Al devenir algo espiritual, se convierte, por una parte, en otro respecto a sí mismo, porque es un "otro" respecto al espíritu. Por otra, permanece él mismo, y esto en dos sentidos: de un lado, viene "hacia sí" en tanto espiritual, porque en sí ya era (potencialmente) espiritual, de lo contrario no podría haber sido captado por el espíritu. Del otro lado es un "otro" respecto al espíritu, y debe serlo: esta era su determinación originaria. Es solamente, o bien potencialmente, espíritu. En principio es algo "material” y un "objeto" del espíritu poético individual.

Ahora bien, si lo otro, lo que ha de ser captado por el espíritu, es ya siempre en sí "espiritual" y, sin embargo -a la vez-, un otro respecto al espíritu, entonces surge la pregunta: ¿qué cambia durante la captación del espíritu?, porque también después de la captación lo captado debe ser ideal, o sea espiritual, y a la vez permanecer otro respecto al espíritu, es decir, no-ideal. ¿Entonces no ha ocurrido nada? Sí y no.

Según Hölderlin, lo que ocurre en ese captar es un potenciamiento, tanto en vista del proceso del poetizar como también en relación a lo que participa del proceso, esto es, en relación al espíritu (del poeta) y a lo otro, al material "transformado y apropiado". ¿En qué medida ocurre un potenciamiento respecto del proceso poético? En la medida que el proceso poético es un proceso del separar y reunir, que solo puede tener lugar si el espíritu "tiene" otro, algo separado del espíritu (todo esto como implicación del "separar"). Ahora bien, esto significa que, si un otro, el material del poetizar, fue captado, entonces el espíritu debe progresar hacia un nuevo otro. Este no es, sin embargo, cualquier otro, sino que debe ser otro que "expanda" la "alteridad" (conforme a la exigencia espiritual de reunificación). Si entonces un otro resulta "transformado y apropiado", entonces el espíritu, según su propia conformación y actividad, debe progresar hacia un otro más abarcador, uniendo a este con los "otros" anteriores. 
La necesidad de expansión del proceso poético descansa pues sobre la estructura fundamental del espíritu con sus actividades, opuestas entre sí, del analizar y sintetizar. De ello resulta el aspecto propio del potenciamiento. Para entender esto debemos considerar con mayor detalle las relaciones constitutivas del captar. Aquello que inicialmente ha de captarse es el material, algo "tomado de la vida". La "captación" del material por parte del poeta ocurre de tal modo que este analiza esto otro, lo fracciona en sus partes, las atraviesa una por una y luego recompone eso otro -el material-, en un todo mediante el recuerdo, es decir, lo sintetiza. Pero ¿cómo puede tener lugar en esto un potenciamiento del material? El potenciamiento ocurre en tanto mediante análisis y síntesis el material obtiene en sí un nexo o conexión incrementada y a la vez resulta delimitado respecto a un "otro". ¿Por qué significa esto un potenciamiento? Resulta significativa aquí la temática básica del "límite" y la "delimitación" y en última instancia la temática del sobrepasamiento de límites. Con ello nos movemos en una de las preguntas fundamentales de la filosofía: ¿por qué es en general algo y no más bien nada?, o bien, ¿mediante qué y gracias a qué "es" en general "algo"?

La filosofía de la Antigüedad griega, que fue importante para Hölderlin precisamente en relación con su controversia con Kant y la cuestión del límite allí planteada (en Kant, especialmente respecto al conocimiento); la filosofía griega, con Platón delante del resto, da la siguiente respuesta, la cual, a mi juicio, tiene en su abstracción una validez sistemática: Algo es solamente sobre la base de que muestra en conexión con otro un límite respecto a este -nos encontramos aquí con la forma más universal de la estructura dinámica, sobre la cual trata nuestro trabajo-. El límite "es", sin embargo, solamente en la mutua implicación de identidad y diferencia. Esto quiere decir que el límite es solamente allí donde correspondencias ("identidades") y diferencias son traídas hacia una conexión (identidad), es decir, allí donde "hay" una "estructura" -siempre dinámica- de la "identidad de identidad y diferencia".

"El límite" surge pues allí donde las diferencias son traídas a una conexión y esta es "fijada por escrito". Pero ¿a través de qué se pueden establecer las diferencias respecto a lo otro? Mediante el "atravesar" lo otro en sus partes, o sea, mediante el separarlo en partes y el subsiguiente recomponer las partes en un todo. ¿Cómo surge de ello un potenciamiento de lo "otro" en sí? Mediante la incrementada cognoscibilidad de este algo a través de su estar atravesado por el espíritu y mediante la delimitación más intensa, así posibilitada, respecto a un "otro" -y esta delimitación significa también un "marcar contorno". Los límites de lo otro se muestran tanto más claramente tanto desde "dentro" como desde "fuera". Ahora bien, llama la atención que tanto "dentro" y "fuera", "algo" y "otro", no puedan ser delimitados definitivamente. Porque si un "otro", un "algo" es atravesado en sus partes, por así decir, "internamente", entonces salta a la vista que es ya en sí una multiplicidad. Pero esto significa que este está determinado en sí, en sus partes, por identidades y diferencias, que sigue ya en sí la dinámica de la alteridad.

Para Hölderlin, un "algo" nunca es un "uno", un "uno" absoluto; es siempre ya en sí una unidad, algo divisible, un nexo. Esto quiere decir entonces que la dinámica mencionada de "algo" y "otro" se despliega en lo "captado" en niveles potencialmente infinitos. Si se "detiene" y "fija” tal dinámica, lo que Hölderlin siempre hace 
en sus estudios, entonces se puede determinar que el potenciamiento de los "algos" equivale a una determinidad más intensa, es decir, a una delimitación de los "algos", tanto desde "dentro" (en el estar atravesado, separado en partes y recompuesto por el espíritu), como desde "fuera" (en la delimitación respecto a lo otro, también posibilitada por ello). Ahora bien, esta dinámica está en sí infinitamente graduada, es decir, potenciada, y los "algos" considerados en cada caso se vuelven más cognoscibles, determinados, "conocidos": ellos experimentan un incremento, un potenciamiento de su "sí mismo".

¿Qué ocurre en estos procesos con el espíritu? Porque este también tiene que ser incrementado, potenciado. Si el espíritu atraviesa lo otro en sus partes y en sus posibles delimitaciones hacia lo respectivamente otro y mediante tal actividad lo otro es determinado más intensamente tanto desde dentro como desde fuera y por ello es potenciado, "incrementado" en tanto sí mismo, entonces ocurre lo mismo con el espíritu. ¿Por qué? Según Hölderlin, el espíritu no puede conocerse a sí mismo solamente por sí mismo -tampoco a nivel trascendental-preempírico-. Para Hölderlin "no funciona" el no-yo, el cual según Fichte debe escindirse del yo absoluto, mediante lo cual entonces se reconoce como él mismo, esto es, "despliega" autoconciencia y se constituye como Yo. Para Hölderlin, el yo requiere un "realmente" otro -también a nivel transcendental-, no un mero no-yo en el sentido de una autoescindirse del yo. Solamente mediante este realmente "otro" el espíritu (poético) puede reconocerse como él mismo.

Si el espíritu atraviesa lo otro en sus partes y sus posibles delimitaciones respecto a lo otro y así lo otro viene incrementado hacia sí mismo, tanto desde dentro como desde fuera, entonces este "conocimiento" de lo otro y su incrementación es posible solamente mediante la constante actividad del espíritu como analítico y sintético. Pero para reconocer lo otro como lo otro en este atravesar y delimitar, el espíritu debe, en esta actividad, constantemente unificarse con ese otro y delimitarse respecto a él. Ahora bien, esto solamente es posible si el espíritu, durante esa actividad, se observa constantemente a sí mismo, es decir, si ocupa constantemente un metanivel y además de esta actividad con lo otro también se separa de sí mismo, es decir, lleva a cabo una diferencia en sí y respecto a sí mismo. Precisamente en esta constante autoescisión y el simultáneo permaneceruno del espíritu consigo, consiste para Hölderlin la formación fundamental del espíritu, el cual se dirige hacia sí, pero solo mediante un "otro". Esto es un modo de reflexión consistente en que el espíritu hace algo y simultáneamente puede "observarse" en ese hacer. Esto ya lo había constatado Kant. Esto corresponde a la conformación fundamental y a la actividad fundamental del espíritu, es decir, el unir y separar, que él puede aplicar también sobre sí. Esta capacidad de la reflexión, de hacer y observarse a la vez, es una determinación fundamental del espíritu humano: la autorreflexividad, que para Hölderlin solo es posible mediante un realmente otro.

Resumiendo, podemos decir que el espíritu se conoce a sí mismo en el atravesar y delimitar, es decir, en el determinar lo otro, y esto es así porque él siempre debe reunir a sí y a lo otro y también separarse de este. Debe reunirse con lo otro para poder conocerlo, y debe separarse de lo otro para poder conocer lo otro como lo otro, como lo que es. Pero el espíritu solo puede hacer esto si a la vez reflexio- 
na sobre sí, es decir, si en ese hacer a la vez se observa en un metanivel. Para ello el espíritu debe hacer lo que es, debe separarse de sí mismo y permanecer uno consigo mismo.

II.

Precisamente en esta dinámica estructural necesaria para todo conocimiento se reconoce el espíritu como él mismo. Esta actividad y conformación fundamental del espíritu, este separar y unir, es el presupuesto transcendental irrebasable de la teoría hölderliniana en su conjunto. Implica a la vez una necesaria interacción entre el espíritu y lo otro. El espíritu no puede efectuar su actividad puramente en sí, lo otro es lo otro y sí mismo solo mediante la actividad del espíritu. No se trata pues de la autorreflexividad del espíritu en el sentido de una subjetividad que se encuentra a la base de la posibilidad del conocimiento, sino de la implicación mutua y la separación del espíritu y lo otro.

Esta dinámica estructural de análisis y síntesis, de identidad y diferencia del espíritu y lo otro es, de acuerdo a su conformación fundamental, constantemente una dinámica duplicada en sí, graduada, porque el espíritu, en tanto unificador y separador, está constantemente en diferencia y unidad respecto de sí mismo. Y él no es simplemente capaz de esta estructura, sino que ella le es necesaria. Esto es posible solamente en el captar de lo otro. Lo que "está a la base" de "espíritu" y "mundo" es la relación entre unidad y diferencia, la relación del espíritu (humano) hacia otro. Solamente a partir de esta relación el espíritu es espíritu, solo a partir de esta relación lo otro es lo otro, lo otro es "sí mismo", lo otro es ("algo").

¿Por qué se potencia el espíritu en el conocimiento de lo otro? ¿Cómo es que "viene" allí "hacia sí mismo" o bien se acrecienta "a sí mismo"? Por una parte, él debe ocupar constantemente un metanivel en la interacción con lo otro. Por otra parte, él se reconoce desde ese metanivel como lo que él es y hace, esto es, unificarse con lo otro y separarse de él, separar en partes eso otro, atravesarlas y sintetizando-reuniendo en el recuerdo, traerlas a una conexión.

Ahora bien, el atravesar y delimitar lo otro significa necesariamente también una delimitación y circunvalación de sí mismo, una separación de lo otro y el atravesarse a sí mismo del espíritu respecto a sus propias partes en sus unidades y en sus diferencias respecto a las partes de lo otro. Un presupuesto para esta posibilidad de la autodelimitación y el conocimiento de lo otro es el metanivel del espíritu en sí, la autoobservación del espíritu. A su vez, el metanivel es la consecuencia necesaria de la captación de lo otro por parte del espíritu. Aquí resulta claro cómo las relaciones de fundamentación del conocimiento nunca pueden ser pensadas en una dirección, linealmente, sino que se confunden como presupuesto y consecuencias, según la perspectiva y el aspecto de lo que se "fija y detiene" en la dinámica. En esto se ve también que en la captación por parte del espíritu se trata de una dinámica paradójicamente compleja, no solo de dos, sino propiamente de cuatro idéntico-diferentes.

El espíritu es un captador -y solo así es espíritu-. En tanto tal, se encuentra siempre al menos en dos niveles, de modo que resulta claro que el conocer lo otro, 
la "transformación apropiadora" de lo otro por parte del espíritu, no significa meramente el incrementado "venir hacia sí", el "devenir sí mismo" del espíritu y de lo otro, sino un potenciamiento. Potenciamiento, por una parte, en la medida en que tiene lugar allí una realización incrementada de los participantes; y por otra parte, en la medida en que la duplicación del espíritu en sí como su "actividad fundamental" no puede permanecer en esta duplicación, sino que esta implica una "duplicación" ulterior, potencialmente infinita. Ahora bien, la "duplicación" potencialmente infinita de un estructura de implicación y explicación desde sí, desde la propia actividad del separar y reunir, significa potenciamiento.

Este potenciamiento quiere decir a la vez un progresar hacia conexiones cada vez mayores, tanto del espíritu como de lo otro. Si el proceso poético comienza con la captación del material, avanza luego hacia el "círculo efectual" y hacia el "elemento", hasta que finalmente alcanza un "mundo". La captación más elevada del mundo y del espíritu, de su individualidad poética, resulta entonces finalmente mediante el opuesto más elevado respecto al espíritu poético individual, es decir, respecto a un "divino". Este "divino" es "infinito", abarcador y es llamado "divino" porque lleva a la cima la "alteridad" de lo otro, presenta aquel extremo de lo otro que no se puede pensar más. A la vez es aquello por captar último y más elevado.

Es notoria y a la vez consecuente la relación entre el espíritu que capta y lo divino por captar. Si lo divino es lo infinito, entonces el espíritu debe captarlo, no para reconocerse en primera línea también como infinito, sino en principio para captar su individualidad. Hay aquí una tensión extrema que se vincula consecuentemente con las relaciones fundamentales ya expuestas. Porque "individualidad" no indica otra cosa que la mayor determinidad e impronta posible del sí mismo. La individualidad poética como forma más extrema de lo delimitado e individualizado se puede conceptualizar solamente en la "controversia" con lo más abarcador, infinito, divino.

Si el espíritu poético ha mediado con lo "divino", entonces puede captar a su mundo y a sí mismo en la medida más determinada y abarcadora, en tanto se ha potenciado mediante las diversas transformaciones apropiadoras en niveles progresivos. Él se conoce a sí mismo y a su mundo, un "mundo en el mundo". Este "conocer", aunque a primera vista así lo parezca, no es ninguna penetración en sentido hegeliano, según el cual esta conduce teleológicamente hacia el concepto y el saber absolutos, sino que en este "supremo" abrirse paso acontece algo trascendentalmente inconmensurable: según Hölderlin el "momento divino" de "sensación trascendental", en el cual lo divino y la individualidad poética son captados, no es más un captar, sino simplemente un "recibir" o "sentir" (aquí Hölderlin no diferencia).

En tal momento tampoco tiene lugar la actividad del espíritu, el separar y reunir en el cambio temporal y en el recuerdo en el tiempo: el espíritu se disuelve en su forma más elevada, en su extremo, como él mismo. Lo mismo vale para el tiempo, en cuya extensión por lo demás el espíritu está activo. En el "momento divino" no hay más tiempo en tanto un tiempo que se extiende; el "momento divino" es, en tanto "instante", tiempo "puro" y a la vez "no-tiempo", así como el espíritu en su "más alta impronta" no es más espíritu. Lo mismo vale para la actividad del espíritu: ella tiene lugar "absolutamente" y a la vez no tiene lugar en el instante; el 
cambio de identidad y diferencia en la extensión temporal, el cual por lo demás es la actividad del espíritu, deviene un cambio "absoluto", un cambio abrupto e instantáneo de identidad y diferencia una en otra; identidad y diferencia se "confunden" absolutamente y momentáneamente.

III.

El "momento divino" de "sensación trascendental" es la primera y última condición de posibilidad (transcendental) del espíritu, de su actividad, del mundo y de lo divino. En el extremo absoluto el fundamento de la actividad del espíritu, identidad y diferencia, se dirige hacia sí de forma extrema, infinita. Ahora bien, esto significa que identidad y diferencia "son" en este instante a la vez absolutamente idénticas y absolutamente diferentes. En este momento es "todo" y "nada" a la vez. En este momento "está ahí" el límite absoluto y a la vez la condición de posibilidad de todo conocimiento. Este momento no puede ser "conocido" o "captado", en él no hay ninguna identidad ni diferencia y, sin embargo, él es la condición de posibilidad, trascendental y a la vez "vivida", "sentida", de todo conocer y poetizar. El espíritu se transforma en "sensación", lo transcendental en vida.

A partir de esta necesaria "cumbre" del proceso poético resulta la posibilidad del poetizar concreto, la posibilidad de que el poema encuentre lenguaje. El presupuesto de esa posibilidad, como se desprende de la conformación del momento divino, es la extrema diferencia -en ese momento- del espíritu respecto a sí mismo y al mundo por él captado. El proceso poético en su punto culminante y la posibilidad del poetizar lingüístico concreto descansan entonces solamente por un lado en el conocer y determinar progresivo de sí y de lo otro. En última instancia -y esto es el doble cambio repentino que ocurre en el "momento divino" de "sensación transcendental" - lo decisivo es la sentida diferencia originaria implicada en el "momento divino", la diferencia como lo originario y "lo que está a la base" (diversa a la identidad en Hegel). Esta diferencia hace posible que el poema encuentre lenguaje.

En la segunda parte del proceso poético, al "momento divino" debe seguir, según Hölderlin, un proceso armónicamente opuesto a la primera parte, que se encuentre bajo el primado de la diferencia: después del momento divino, el mundo transformado-apropiado y configurado por el poeta debe aparecérsele como desconocido, el poeta no puede asumir nada como dado; lo que él se ha apropiado y ha configurado para sí durante todo el proceso anterior debe aparecérsele como completamente ajeno, él no puede tener ningún nombre, ninguna palabra, tiene que reapropiarse su mundo paso a paso en un atravesar bajo signo inverso, tiene que dejar hablar y llevar a lenguaje lo propio-ajeno.

Apropiarse de lo otro sin superarlo en su alteridad, desplegar "su mundo" y su individualidad, siempre dinámicamente, sentir el cambio repentino "absoluto" de identidad y diferencia así como la diferencia originaria en el instante más elevado, recibir el propio mundo después del momento divino como infinitamente ajeno, volver a penetrarlo: estos son los "mundos en los mundos" y los permanentes "sobrepasamientos de límites", de los cuales trata la poética de Hölderlin y que pueden ser significativos en una perspectiva social, cultural e intercultural. 


\title{
RESUMEN
}

El presente trabajo se centra en la concepción sobre identidad y diferencia que aparece en los estudios poetológicos de Hölderlin. La tesis interpretativa consiste en que los análisis de Hölderlin sobre el espíritu poético ofrecen una noción de diferencia que no se deja subsumir bajo el predominio de lo idéntico. Para validar esta tesis, se analizan los desarrollos acerca de "sobrepasamiento de límites" y "el mundo en el mundo", presentes en el texto El modo de proceder del espíritu poético.

Palabras clave: Hölderlin, poetología, diferencia, sobrepasamiento de límites, mundo.

\begin{abstract}
This work is focuses on the concept of identity, and difference that appears in the poetologic studies of Hölderlin. The interpretative thesis is that Hölderlin's analysis regardng the poetic spirit offers a notion of difference that cannot be limited to the predominance of the identical. In order to validate this thesis, the author analyzes the developments regarding "overflow of limits" and "world in the world", present in the text El modo de proceder del espíritu poético.
\end{abstract}

Key words: Hölderlin, Poetology, Difference, Overflow of limits, and "world in the world". 